\title{
The Kiricuta Procedure for Chest Wall Reconstruction after Amputation of Right Upper Extremity-Infected Melanoma
}

\author{
Natalia Papastergiou and Olivier Borens
}

\begin{abstract} common free or vascularized flaps. using the Kiricuta procedure.

C HEST WALL RECONSTRUCTION is a challenging procedure after major amputations and debridements. Patients may need flap coverage for effective treatment but often have multiple medical problems, necessitating a safe means of incision coverage with minimal morbidity. A number of flaps exist for thoracic reconstruction, however, if the resection is large and these flaps cannot cover the defect, another flap must be used: the omentum flap. Kiricuta [1] was the first to describe and publish the use of the omentum flap for the coverage of a defect after breast cancer surgery in the 1960s. The most common indications for chest wall reconstruction in which the omentum flap can be used are the repair of defects caused by infection, tumor ablation, radiation necrosis, congenital deformities, and trauma [2].
\end{abstract}

Background: Huge defects after surgical resection of upper extremity lesions can be difficult to cover with

Case Presentation: The case of a 65-year-old female patient with a huge exulcerated and infected (pseudomonas, proteus and enterococcus) melanoma with multiple arterial metastases of the right upper extremity is presented. The tumor was treated by amputation of the right upper extremity and the defect was covered by

Conclusion: This omentum flap seems to be a useful alternative particularly in large defects in upper extremities.

\section{Case Presentation}

We describe a 65-year-old female right-handed patient who presented with a slowly evolving lesion on her right upper extremity and hemithorax (Fig. 1) over a four-year period. She consulted the dermatology department where a biopsy confirmed a huge exulcerated acral lentiginous melanoma (ALM) with a Breslow more than $1 \mathrm{~mm}$, type pT4 N3 M0, stage IIIC.

Magnetic resonance imaging (MRI) as well as positron emission tomography (PET) scan showed multiple arterial metastases of the right upper extremity and cervico-thoracic infiltration of the soft tissue as well as infiltration of the right breast (Fig. 2). The tumor volume was calculated as $11 \times 14 \times 10 \mathrm{~cm}$. No distant metastases were observed. Because of the size of the tumor, the inflammatory reaction of the upper extremity, and in the absence of distant metastases, amputation of the upper right extremity was indicated.

To eliminate all invaded or inflammatory tissue, soft tissue resection had to be conducted up to the costal grill. To cover such a major soft tissue defect the Kiricuta procedure was chosen.

After amputation of the right upper extremity (through the scapulo-costal and the sterno-clavicular joint) with combined mastectomy and resection line up to $3 \mathrm{~cm}$ proximal of the pelvic crest, the costal grill was debrided up to the periosteum and the inter-vertebral muscles. The entire defect (right hemithorax) was then covered with a vacuum-assisted closure (VAC) dressing. Three days later, the greater omentum was mobilized after colo-omental detachment and release of the greater curvature through laparotomy. The omentum pedicle flap then was used to cover the entire incision surface and covered with splitskin graft. In addition to a small necrosis of the omentum in the upper anterior chest region that needed debridement and a new split-skin graft, recovery was uneventful.

In the post-operative period, the patient presented with a pulmonary embolism that was treated by anti-coagulation.

Département de l'appareil locomoteur, Centre Hospitalier Universitaire Vaudois, Service d'orthopédie et traumatologie, University of Lausanne, Lausanne, Switzerland.

(C) Natalia Papastergiou and Olivier Borens 2016; Published by Mary Ann Liebert, Inc. This Open Access article is distributed under the terms of the Creative Commons License (http://creativecommons.org/licenses/by/4.0), which permits unrestricted use, distribution, and reproduction in any medium, provided the original work is properly credited. 

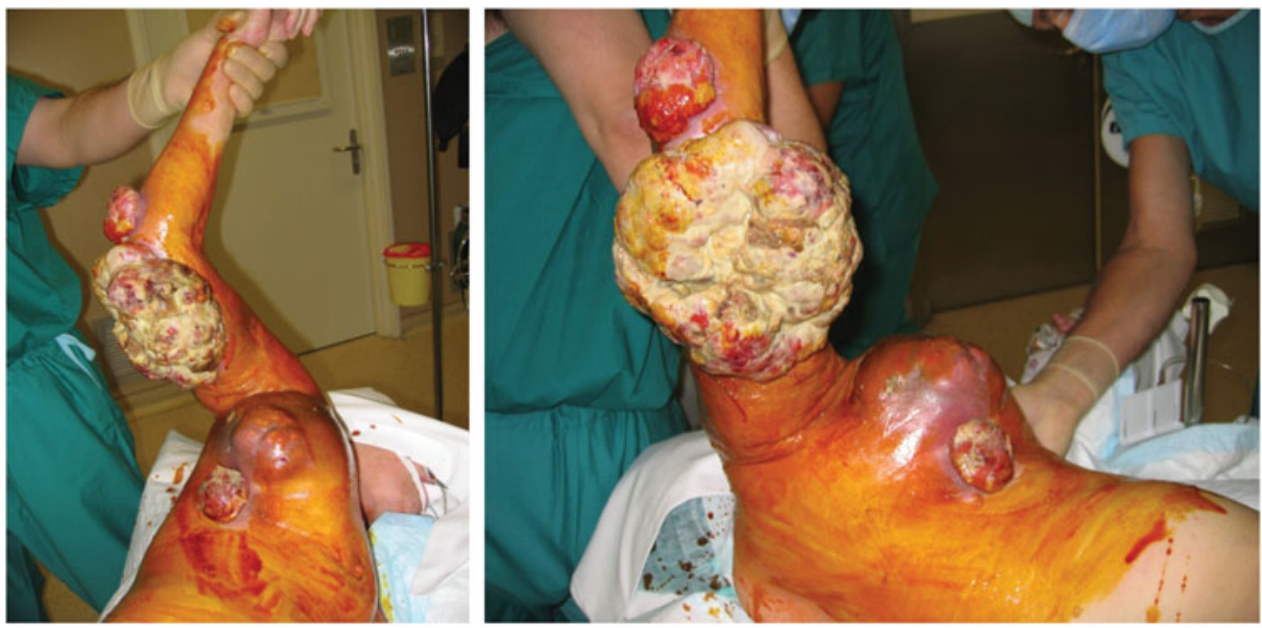

FIG. 1. Images of lesions.

Because of the extensive operations, the patient had equilibrium problems when walking but improved rapidly with physiotherapy (Fig. 3).

Three months later, pulmonary, hepatic and bone metastases (in dorsal vertebral [D6] and in left humerus) appeared and the patient received radio- and chemotherapy (temodal) to relief pain symptoms. One year post-amputation, a pathologic fracture occurred in her left humerus and was nailed. She died 3 months later.

\section{Discussion}

Chest wall reconstruction can be complex and may require a multi-disciplinary approach. The value of the Kiricuta flap is its large size, long pedicle, and its angiogenic and immunogenic characteristics. For these reasons, it is known as the protector of the abdominal cavity. It can provide similar properties in chest wall reconstruction of infected or radiated tissues. Moreover, its plasticity, versatility, and its relative

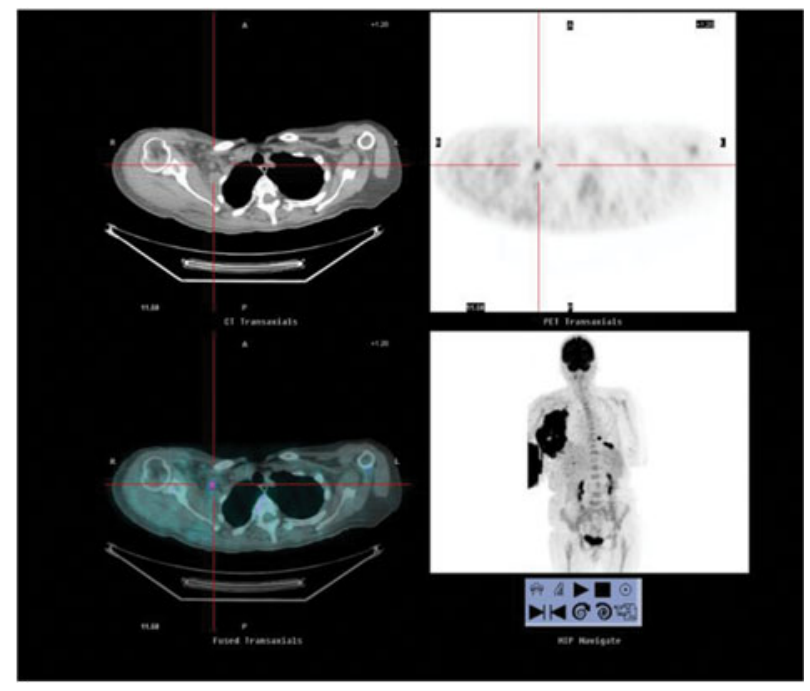

FIG. 2. Patient's positron emission tomography (PET) scan showed multiple arterial metastasis of the right upper extremity and cervico-thoracic infiltration of the soft tissue as well as infiltration of right breast. ease of harvesting make it appropriate in reconstructive procedures of large defects. It can be used as a free graft or may be revascularized by microsurgery. The omentum flap can be transferred to any site, especially to the upper chest [3].

However, the use of omentum is not without limitations. Flap harvest necessitates a laparotomy, which cannot always be performed in patients with respiratory failure, after multiple abdominal operations [4], or with intra-abdominal metastases. The use of laparoscopic techniques facilitates the harvesting of the omentum, making it appropriate in the treatment of patients with multiple comorbidities. It is also difficult to predict flap size precisely pre-operatively because the volume of the greater omentum has no direct correlation with the patient's morphologic characteristics [5]. Furthermore, if the tumor necessitates the resection of a part of the costal grill (more than three ribs) the thoracic cage is not stable and pulmonary complications may occur in these situations. Prosthetic material or another myocutaneuous flap can be alternatives [6].

Additionally, donor site complications have been reported that include ventral hernia, surgical site infection, ileus, upper gastrointestinal hemorrhage, small bowel obstruction, postoperative hemorrhage from partial avulsed pedicle, and delayed spleen rupture. General complications such as pulmonary dysfunction, cardiac dysrhythmias, deep venous thrombosis, pulmonary embolus, neurologic dysfunction, and renal insufficiency have also been described [3].

A variety of flaps, both single and in combination, could be used to achieve coverage of the chest wall after extirpative surgery. The reconstructive choice depends on factors such as the size of the defect, location on the chest wall, arc of rotation of the flap, and availability of recipient vessels. Chang et al. [7] defined the limit between a small and large defect at $300 \mathrm{~cm}^{2}$.

If the chest wall defect is superficial and small, local flaps or a skin graft may be reasonable choices for incision closure as the thoraco-epigastric (or transverse abdominal) flap and local fasciocutaneous flap, such as the scapular and/or parascapular flaps. In general, these relatively small fasciocutaneous flaps are used rarely in chest wall reconstruction after a large defect as in our case, except perhaps in combination with other flaps for large defects.

The majority of chest wall reconstructions for extensive disease may be treated with pedicled regional flaps. In additon to the omentum flap, plastic surgeons often use the latissimus 

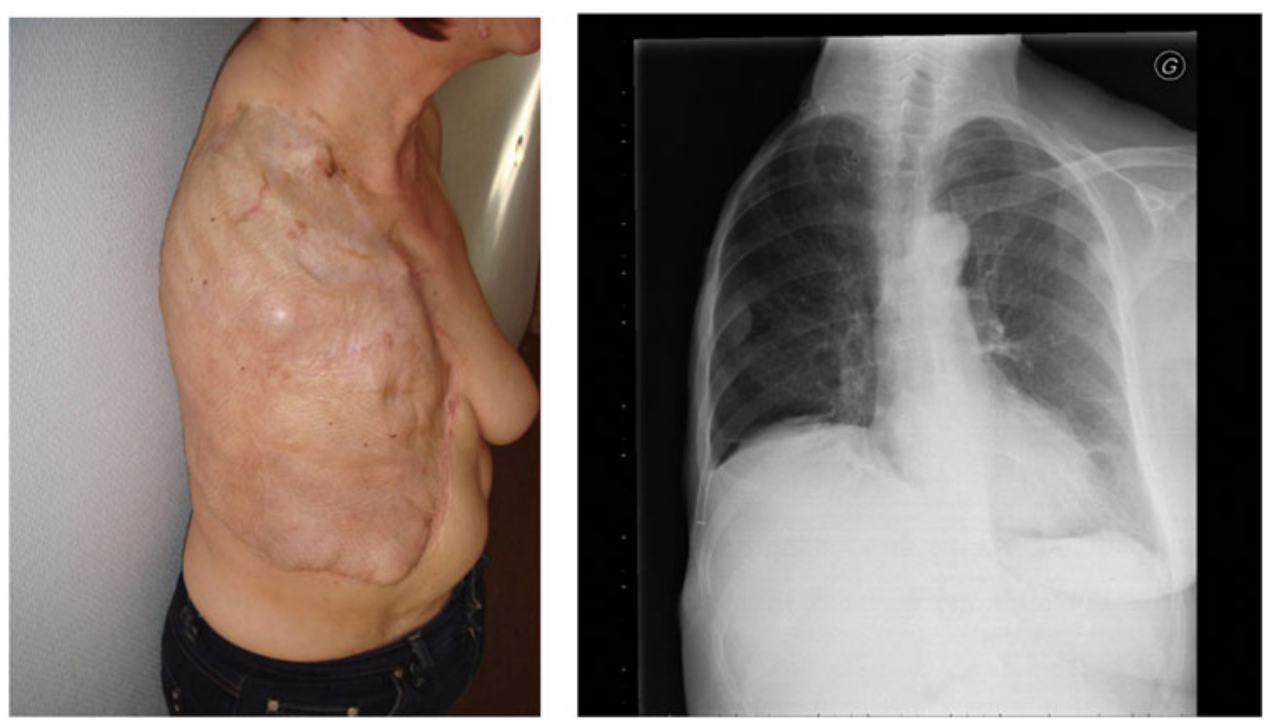

FIG. 3. Final results of the procedure and thoracic radiograph.

dorsi, the rectus abdominis, and the pectoralis major flaps. If necessary, they utilize microvascular techniques if there is any difficulty of flap reach or vascularity [8]. Situations in which an omentum flap is indicated, or even mandatory, are those in which a free or local flap is impossible to use for covering huge, infected, and irradiated defects [9].

\section{Conclusion}

The omentum flap remains an extreme flap for extreme situations. As in our case this flap is suitable for repair of complex infected large soft-tissue defects after extensive cancer surgery.

\section{Author Disclosure Statement}

No competing financial interests exist.

\section{References}

1. Kiricuta I. [The use of the great omentum in the surgery of breast cancer]. La Press Médicale 1963;71:15-17.

2. Skoracki RJ, Chang DW. Reconstruction of the chestwall and thorax. J Surg Oncol 2006;94:455-465.

3. Hultman CS, Culbertson JH, Jones GE, et al. Thoracic reconstruction with the omentum: Indications, complications, and results. Ann Plast Surg 2001;46:242-249.

4. Petit JY, Lasser P, Fontaine F. [Use of omental flap in the course of evolution of treated breast cancer. Apropos of 20 omental flaps done at the Gustave-Roussy Institute]. Bull Cancer 1977;64:659-665.

5. Cothier-Savey I, Tamtawi B, Dohnt F, et al. Immediate breast reconstruction using a laparoscopically harvested omental flap. Plast Reconstr Surg 2001;107:1156-1163.

6. Losken A, Thourani VH, Carlson GW, et al. A reconstructive algorithm for plastic surgery following extensive chest wall resection. Br J Plast Surg 2004;57:295-302.
7. Chang RR, Mehrara BJ, Hu Q-Y, et al. Reconstruction of complex oncologic chest wall defects: A 10-year experience. Ann Plast Surg 2004;52:471-479.

8. Cordeiro PG, Santamaria E, Hidalgo D. The role of microsurgery in reconstruction of oncologic chest wall defects. Plast Reconstr Surg 2001;108:1924-1930.

9. Micheau P. [The greater omentum. Its role in reconstructive plastic surgery]. Ann Chir Plast esthétique 1995;40:192-207.

Address correspondence to: Dr. Natalia Papastergiou Département de l'appareil locomoteur Centre Hospitalier Universitaire Vaudois Service d'orthopédie et traumatologie University of Lausanne Rue du Bugnon 46 1011, Lausanne Switzerland

E-mail: Nataliapapastergiou@yahoo.com

\begin{tabular}{|c|} 
Abbreviations Used \\
$\mathrm{ALM}=$ acral lentiginous melanoma \\
$\mathrm{MRI}=$ magnetic resonance imaging \\
$\mathrm{PET}=$ positron emission tomography \\
$\mathrm{VAC}=$ vacuum-assisted closure
\end{tabular}

Cite this article as: Papastergiou N, Borens O (2016) The Kiricuta procedure for chest wall reconstruction after forequarter amputation of infected melanoma. Surgical Infections Case Reports 1:1, 120-122, DOI: 10.1089/ crsi.2016.0028 